\title{
Exploring Difficulties Faced in Teaching Elective English Listening Courses at Japanese Universities
}

Marc Jones, University of Portsmouth

Marc.Jones@myport.ac.uk

Version of record: Jones, M. (2020) Exploring Difficulties Faced in Teaching Elective

English Listening Courses at Japanese Universities. Listening Education Online

Journal, 10(1), 12-20.

\begin{abstract}
This paper is an exploration of the problems encountered by the author while teaching two elective English listening courses at private Japanese universities in 2017 and 2018. Problems arose regarding classroom temperature and student expectations of passive involvement. Further issues discussed are processing limitations due to working memory and state of phonological acquisition, motivation, general listening pedagogy and assessment along with attempted solutions in order to inform administrators and classroom practitioners who may be planning or teaching foreign language listening courses.
\end{abstract}

Keywords: foreign language; higher education; English; motivation; pedagogy

\section{Introduction}

This article is based upon my experiences as the instructor for listening classes at two Japanese private universities. One university is located in the Tokyo suburbs and one in Yokohama. The class in Tokyo was studying an 'Authentic Listening' (AL) course in 2018, while the class in Yokohama was studying an 'English through Songs' (EtS) course in 2017. Both courses were elective modules open to undergraduate students from first to fourth year.

While students want to improve listening, there are difficulties involved. Despite 
a substantial body of literature with pedagogical recommendations, there are few reports of teacher practice detailing teacher and learner affect. In this article I shall review the literature on listening pedagogy then document the problems faced and attempted solutions.

\section{Literature Review}

For years listening instruction has appeared controversial (Vandergrift, 1997; Flowerdew \& Miller, 2005; Field 2008) yet examples of good practice in the literature are in accord. There is agreement on a mixture of bottom-up decoding skills as well as top-down processing skills to compensate for difficulties in decoding at the phonemic and lexicogrammatical levels.

Regarding top-down skills, Vandergrift (1997) and Goh \& Aryadoust (2015) advocate cognitive and metacognitive strategies, for example, applying knowledge of genre and context to listening texts. Field (2008) also advocates a move from the “comprehension approach" (CA) (Field, 2008: ch. 2, p. 2/17) toward a process approach, where learners apply both bottom-up and top-down processes, as opposed to listening for answers to preset comprehension questions.

Working with adult learners of English as a foreign language (EFL), one cannot presume the L1 and L2 phonological systems are the same, nor that learners have acquired the entire English phonological system; therefore part of listening lessons should provide affordances for phonology acquisition, at least for receptive purposes. How phonology is acquired is not completely clear but it appears that naive language learners may have problems with novel phonemes, which may initially be categorised as non-speech sounds, according to Best's (1995) Perceptual Assimilation Model (PAM). L2 phonemes that may be allophones in L1 may move to an L2 category assignation for 
more experienced listeners, according to Flege's (1995; 2003) Speech Learning Model; for less experienced listeners they are likely to move to the nearest L1 assignation, according to Kuhl's (1992; 1994; Kuhl et al, 2008) Native Language Magnet model.

To develop receptive phonology, Hardison (2018) increased visual salience by gating video, (i.e., clipping video to target phonemes and extending onwards to complete a word and/or utterance gradually) which caused subjects to be more likely to hear target consonants and identify words in her study more effectively, either when listening to video or audio only. This makes sense if we apply what Pienemann (2003) says about morphology to phonology: what is unable to be processed cannot be acquired. This approach may also prove useful at the utterance level, especially with connected speech, to assist in correcting the problem observed by Bonk (2000) where "Nearly a quarter of the 59 students tested were not able to make sense of connected L2 speech even when they knew all the words used in the text." (Bonk, 2000, p. 27.) With features of linguistic items becoming more salient, parsing such items may become easier.

Unfortunately, creating gated videos requires time that many teachers do not have, therefore, additional methods are still required. Field (2008) promotes an approach that mixes bottom-up decoding with top-down strategies while Goh (1998) advocates a greater emphasis on bottom-up decoding for less proficient listeners and top-down strategies for more proficient listeners. However, learners may have problems in applying strategies to their listening. Siegel (2014) advocates teacher modelling as a useful way to provide listening instruction, and this can be applied to use of strategies. This should provide learners in L2 classrooms with greater understanding in techniques their teacher is instructing them in, rather than the transformation of instruction where learners do something similar but perhaps not the same as the teacher's intention. 


\section{Problems encountered}

\section{Course expectations}

One problem with both courses was that being electives, some students selected them due a perceived light workload. I know this was the case for at least one EtS student because they told me explicitly. However, this too is also documented; as Siegel (2014) notes, some learners in Japan are accustomed to passive language learning rather than cognitively challenging work. I ascribed the apparent lack of motivation among some students in the class to this. The professor in charge of part-time instructors at that particular university had provided prior warning that some students may be seeking a passive experience because it had been a problem in prior iterations of the course before I had taught it.

The scheduling of the classes was also an issue; the EtS class was after lunch on Wednesday and the AL class was scheduled for 90 minutes on Friday afternoon. The heat of the classrooms in buildings with centrally controlled air conditioning was conducive to students feeling tired, particularly in summer, which affected attention.

\section{Motivation}

Another problem in both courses pertains to the psychology of learners in a wider area than listening pedagogy. Amotivation is "a state in which one either is not motivated to behave, or one behaves in a way that is not mediated by intentionality." (Ryan \& Deci, 2017: 190) This amotivation in the listening class may arise from: learners perceiving in themselves a lack of satisfactory proficiency which task completion would require; a belief that participation in the act (in this case attempting to listen) would not result in a desired outcome (parsing the speech stream); a perception of low utility in the task; or a lack of prior exposure to the particular type of instruction. 
Due to the classes being chosen as elective courses I believe most students perceived utility in listening tasks. However, self-efficacy may be low due to listening instruction being neglected at the high-school level and therefore inconsistent listening instruction received prior to the elective class. Furthermore, lack of experience with a combination of bottom-up and top-down process instruction may also have created a state for some learners to perceive incorrectly that the instructional method was overly novel and therefore ineffective.

Ways that I chose to mitigate amotivation in the classes were by selecting materials that I was passionate about and negotiating text selection with students, as per Breen \& Candlin's (1980) recommendation. I told students which tasks were possible with one week to prepare, chosen by a show of hands in the classroom. Tasks were proposed with consideration of all students in the room who would need to share audio equipment and undertake whole-class instruction,

\section{Signal Processing}

In spite of learner expectations, the courses were demanding. This was partly due to the classroom conditions, and partly due to the sustained attention required to process the auditory signal. This appeared more problematic for students with erratic attendance than those with regular attendance, and I ascribe this to less practice both in paying close attention to listening texts and using working memory to process longer streams of speech than regular attendees.

Working memory, according to Baddeley (1992) is composed of three components, the Visuo-Spatial Sketchpad, the Phonological Loop and the Executive Function. The Phonological Loop is used to process speech, while the Executive Function processes the need to act based upon stimuli. Information from the 
Phonological Loop is either retained in working memory, sent to long-term memory or else lost. When the Phonological Loop is in constant use and the Executive Function is processing information and deciding how to act, the system becomes stressed and thus information is lost without being retained in either working memory or long-term memory.

Such loss of information means listeners lose out on the meaning from the auditory signal. This problem was mitigated by pausing recordings and/or by providing several opportunities to listen to the same part of the recording. I also used what Field (2008) refers to as "micro-listening activities ... they ideally feature single sentences, pairs of sentences or very short sections of text, drawn from published, off-air or internet recordings". (Field 2008: ch. 5 p. 24/33)

Another strain on cognitive abilities is the complexity of the language. As Robinson (2003) states, length of time on task causes diminishing attention which in turn causes "failure to correctly identify and interpret auditory input (in studies of comprehension)" (p.652). Certainly, it is more difficult to maintain attention to an auditory signal while processing phonemic values and also processing lexicogrammatical features such as time markers from features with low salience such as verb endings, and reference from pronouns which could repeat depending on the different subjects and objects of the speech act.

There is also the complexity of the auditory signal itself to deal with, such as background noise and phonemic quality in relation to norms that learners have internalised in L1 acquisition (Flege 1990; Kuhl 1992). When phonemes are acquired, they are either learned 'as is' if they are extremely unique in comparison to the learner's first language (Flege, 1990); if they are similar they are mapped as equivalents to the 
closest similar first language phonemes (Best, 1995; Kuhl, 1992) though Flege asserts that L1 and L2 differences can be acquired over time.

Students in the courses had differing levels of exposure to spoken English, and differing levels of exposure to varied Englishes. In practical terms, the students with least exposure to English have less developed L2 phonology and therefore have problems perceiving and processing the auditory signal accurately. For such students, the metacognitive strategy of refocusing attention using selective attention (Vandergrift \& Tafaghodtari, 2010) was taught, with learners reminded to write notes during silences while the recording was paused. This had mixed success: it avoided complete dysfunction in listening, with all students eventually returning focus to the auditory stream rather than allowing negative affect to distract them from decoding the text.

\section{Assessment}

Summative assessment of student listening was problematic for the AL class due to differences between my beliefs and student expectation regarding listening pedagogy. Tests of listening should assess only listening; however multiple-choice items implicitly test a synthesis of reading and listening skills, and transcription tests writing skills, and may be unreliable due to lack of knowledge of phoneme-grapheme correspondences. However, all students were English majors therefore I decided it was unproblematic. A combination of multiple-choice items and transcription was also used for formative assessment in the EtS class as well as summative assessment by presentation, discussed in more detail below.

Additionally, because phonology is acquired at different speeds depending on the learners, it is unfair to ascribe university credits to only one aspect of listening. Because the EtS class had been assessed summatively by the previous teacher through 
presentations about songs chosen by the learners, I felt this would provide a clear reason for independent listening outside the classroom.

With the AL class, I presumed that phoneme-grapheme correspondences were largely no problem and that due to the university program's mandatory extensive reading thread, that most students were fluent readers. Therefore a benchmark, midterm and summative test were used. This allowed me to assess the level of learners' phonological acquisition, providing the information about the highest accuracy that the learners could attain, with the caveat that tests are snapshots of ability on one day. While learners gained listening skills, the tests used reflected the difficulty in using those skills without the kind of teacher direction in lessons and therefore scores were lower than expected despite evidence of students decoding natural speech.

\section{Limitations}

The above factors are problems faced in the author's elective classes in private universities in Japan. One limitation of the data is that it is highly subjective and therefore may not generalize to language teaching worldwide. However, it is truthful and details of problems faced and possible solutions thereof may be useful for administrators or classroom practitioners planning or conducting foreign language listening courses.

\section{Summary}

Clearly there are many factors that affect teaching and learning, both human and aspects of the physical classroom environment. While teacher-related aspects are easier to control than environmental factors, they are by no means simple due to emotion, or sound pedagogical decision-making conflicting with desires of some students to avoid 
participation in class work or engage in tasks they find either unappealing or perceive unlikely to achieve to a satisfactory standard.

Declaration of interest statement: I declare that there is no conflict of interest in the work. This paper has been produced without internal or external funding.

References:

Baddeley. (1992). Working Memory. Science, 255(5044), 556-559

Best C. T. (1995) A direct realist view of cross-language speech perception, in Strange, W. (ed.) Speech Perception and Linguistic Experience. Timonium, MD: York Press. 171-206.

Bonk, W. J. (2000) Second Language Lexical Knowledge and Listening Comprehension, International Journal of Listening, 14:1, 14-31.

Breen, M. P., \& Candlin, C. N. (1980). The essentials of a communicative curriculum in language teaching. Applied linguistics, 1(2), 89-112.

Field, J. (2008) Listening in the Language Classroom (ebook). Cambridge: CUP.

Flege, J. (1995) Second-language Speech Learning: Theory, Findings, and Problems. In Strange, W. (Ed) Speech Perception and Linguistic Experience: Issues in Crosslanguage research. Timonium, MD: York Press, pp. 229-273.

Flege, J. (2007) Language contact in bilingualism: Phonetic system interactions. In Cole, J. \& Hualde, J. I. (Eds.), Laboratory Phonology 9. Berlin: Mouton de Gruyter, pp. 353-380.

Flowerdew, J., \& Miller, L. (2005). Second language listening: Theory and practice. Cambridge University Press.

Goh, C.C.M. (1998) Strategic processing and metacognition in second language listening Examining comprehension strategies and tactics, metacognitive 
knowledge and listening ability. (Doctoral Dissertation) Lancaster University, UK.

Goh, C.C.M. \& Aryadoust, V. (2015) Examining the Notion of Listening Subskill Divisibility and its Implications for Second Language Listening. International Journal of Listening, 29(3), 109-133.

Kuhl P.K. (1992) Psychoacoustics and speech perception: internal standards, perceptual anchors, and prototypes. In: Werner L.A, Rubel E.W. (ed.) Developmental psychoacoustics. Washington, DC., American Psychological Association.

Kuhl P.K. (1994) Learning and representation in speech and language. Current Opinion in Neurobiology. 1994;4:812-822.

Kuhl, P. K., Conboy, B. T., Coffey-Corina, S., Padden, D., Rivera-Gaxiola, M., \& Nelson, T. (2008). Phonetic learning as a pathway to language: new data and native language magnet theory expanded (NLM-e). Philosophical Transactions of the Royal Society B: Biological Sciences, 363(1493), 979-1000.

Pienemann, M. (2003) Processability Theory. Doughty, C. J. \& Long, M. H. (ed.) (2003) The Handbook of Second Language Acquisition. Blackwell.

Robinson, P. (2003) Attention and Memory during SLA. Doughty, C. J. \& Long, M. H. (ed.) (2003) The Handbook of Second Language Acquisition. Blackwell.

Ryan, R. M., \& Deci, E. L. (2017). Self-determination theory : basic psychological needs in motivation, development, and wellness. New York, The Guildford Press.

Siegel, J. (2014) Exploring L2 listening instruction: examinations of practice. ELT J 2014; 68 (1): 22-30. doi:10.1093/elt/cct058 
Vandergrift, L. (1997) The Cinderella of Communication Strategies: Reception Strategies in Interactive Listening. The Modern Language Journal, 81(iv) 494505

Vandergrift, L. \& Tafaghodtari, M. H. (2010) Teaching L2 Learners How to Listen Does Make a Difference: An Empirical Study. Language Learning 60(2), 470497 